\title{
Data and Knowledge for Medical Decision Support
}

\author{
Jana Zvárová ${ }^{1}$ \\ ${ }^{1}$ Editor-in-Chief, European Journal for Biomedical Informatics, Prague, The Czech Republic
}

The EFMI Special Topic Conference Data and Knowledge for Medical Decision Support held in Prague, The Czech Republic, April 17-19, 2013 (www.stc2013.org) reflected opportunities, challenges and priorities of data and knowledge for medical decision support. The conference was organized by the European Federation for Medical Informatics (EFMI) in cooperation with the Society of Biomedical Engineering and Medical Informatics of the Czech Medical Society J. E. Purkyne. Nearly thirty years after the conference Computer-aided medical decision making held in Prague 1985 [1] this conference showed many new developments of methods and systems focused on medical decision support. Medical decision support is increasingly important. It has spawned research in the areas of standardization, semantic interoperability, formalization of knowledge, knowledge discovery and guidelines. It also led to the development of decision support systems that can be interfaced with clinical information systems. It is very important that the quality of these systems is carefully evaluated. Apart from being used by decision support systems the current medical knowledge also has to be managed so that it is easily accessible by physicians and nurses. Medical decision support is an important constituent in different eHealth applications. Most of the developed decision support systems can be more or less easily integrated into clinical information systems both as part of those systems connected through standardized interfaces or as services to be remotely accessed.

As an outcome of the conference selected full papers in limited number of pages were published by IOS Press [2] and short abstracts of all submissions were published in the International Journal for Biomedicine and Healthcare (www.ijbh.org). In the year 2013 (Volume 9) European Journal for Biomedical Informatics is publishing selected reviewed papers of the conference without restriction on the number of pages. Authors are not paying an article processing fee for the immediate release of peer-reviewed articles, but a small financial support is required in case that the support of projects or sponsors is acknowledged (see Instruction to authors).

Beginning in 2013 (Volume 9) European Journal for Biomedical Informatics will ask authors for translation of structured abstract of the paper to at least one European language. EJBI provides immediate open access to peerreviewed papers, which will be published in the running first issue of EJBI during each calendar year. The other issues of EJBI are special issues related to different biomedical informatics topics. Topics for special issues can be proposed to editor-in- chief of EJBI using the form Proposal of EJBI special issue for further processing. Topic for special issue is specified by an open call or by a special event.

We invite you to propose special topics that would help to accelerate needed changes in health care by easy transfer of a new information and knowledge for health care delivery.

\section{References}

[1] Jan H. van Bemmel, Francois Grémy, Jana Zvárová (eds.): Diagnostic Strategies and Expert Systems. Elsevier, North Holland, Amsterdam 1985.

[2] Arie Hasman, Bernd Blobel, Jana Zvárová (eds): Data and Knowledge for Medical Decision Support. IOS Press, Amsterdam 2013. 